\title{
Dar es-Soltane
}

G. Souville et D. Ferembach

\section{(2) OpenEdition \\ Journals}

Édition électronique

URL : http://journals.openedition.org/encyclopedieberbere/2215

DOI : 10.4000/encyclopedieberbere.2215

ISSN : 2262-7197

\section{Éditeur}

Peeters Publishers

\section{Édition imprimée}

Date de publication : 1 avril 1995

Pagination : 2226-2229

ISBN : 2-85744-808-2

ISSN : 1015-7344

\section{Référence électronique}

G. Souville et D. Ferembach, « Dar es-Soltane », Encyclopédie berbère [En ligne], 15 | 1995, document

D14, mis en ligne le 01 juin 2011, consulté le 25 septembre 2020. URL : http://

journals.openedition.org/encyclopedieberbere/2215; DOI : https://doi.org/10.4000/ encyclopedieberbere.2215

Ce document a été généré automatiquement le 25 septembre 2020.

(C) Tous droits réservés 


\section{Dar es-Soltane}

\section{G. Souville et D. Ferembach}

1 Important site préhistorique du Maroc, proche de Rabat, comptant plusieurs gisements.

\section{Grotte I (G. Souville)}

2 Elle est située à $600 \mathrm{~m}$ de l'ancien pavillon d'été du Sultan, à $300 \mathrm{~m}$ du rivage actuel. Cette grotte, qui s'ouvre dans une falaise morte, fut fouillée en 1937 et 1938 par A. Ruhlmann. L'entrée était occupée par un amas coquillier et la cavité était comblée jusqu'au plafond en grès dunaire. A. Ruhlmann y distingua 13 niveaux dans lesquels il voyait la succession d'un Atérien inférieur, d'un Atérien récent, d'un « Moustérien décadent " et des industries récentes qualifiées de Néolithique ancien auxquelles succédait une couche supérieure renfermant des documents d'âge historique (romain et arabe). Cette stratigraphie suscita une abondante littérature et de multiples discussions non dépourvues de polémique. Le remplissage de la grotte s'est effectué dans la deuxième partie du dernier pluvial et avant l'Ouljien. Cette sédimentation fut appelée Soltanien et remplaça le Grimaldien dans la classification du Quaternaire marocain. 


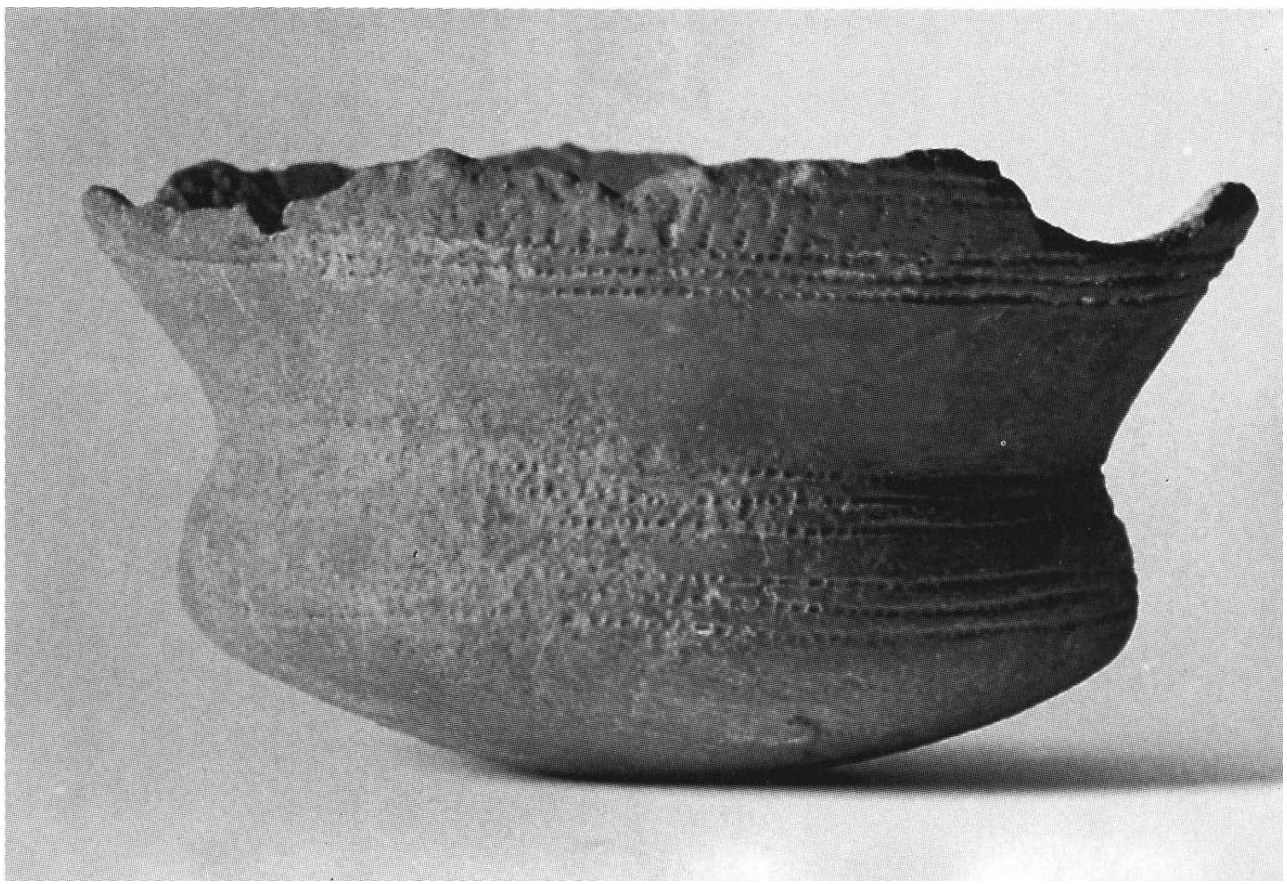

Tessons décorés au peigne de tradition campaniforme de Dar es-Soltane (Photo Kostomaroff)
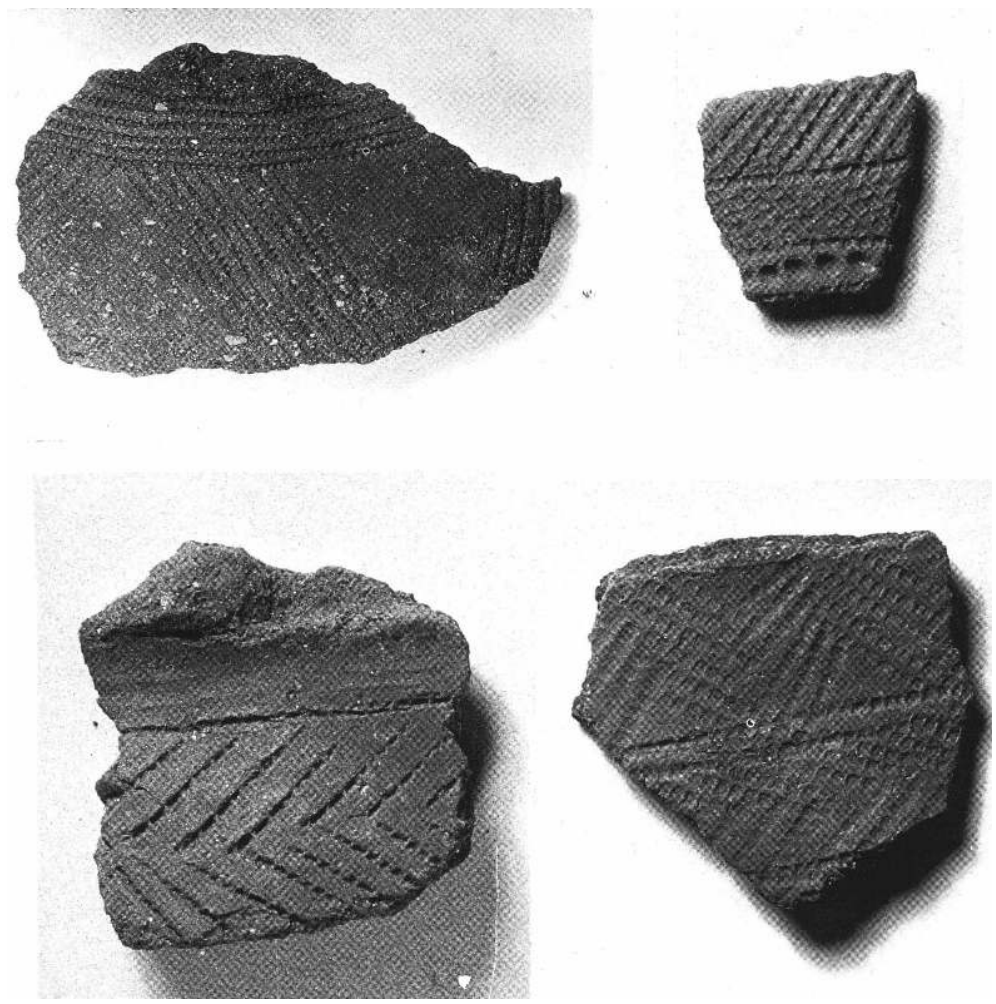

3 L'industrie lithique, les objets en os, la poterie, la faune et des restes humains ont été trouvés en abondance dans ce gisement. La couche A est d'âge historique (monnaie d'Hadrien, monnaie arabe, bracelet de bronze) ; la couche B est un amas coquillier épais de 1,60 m; Ruhlman l'attribua au Néolithique ancien, en fait, il s'agit d'un Chalcolithique affirmé offrant de nombreux tessons campaniformes décorés au peigne 
et un vase entier à col en pavillon très proche des produits du Guadalquivir et du Portugal. Parmi les instruments en os, il fut trouvé une spatule à bords dentés qui servit à décorer la poterie par impression. Un brassard d'archer, en pierre, confirme l'appartenance de cette industrie au Campaniforme. La couche

4 C1 immédiatement sous-jacente au niveau chalcolithique fut attribuée par A. Ruhlmann à un "Moustérien décadent ». Le débitage d'éclats grossiers ne présente aucun caractère précis qui puisse appuyer cette attribution. Les uns y virent une industrie épipaléolithique, les autres (M. Antoine, J. Roche) un faciès du Néolithique ancien. En fait aucun caractère néolithique ne fut jamais reconnu dans cette industrie.

Le niveau $\mathrm{C} 2$, caractérisé par une pointe marocaine, des pièces foliacées bifaciales et un débitage levallois appartient à un Atérien évolué sinon final. Une mesure du C 14 indique que cette couche est antérieure à 27000 ans. L'Atérien était déjà présent dans la couche 1 , antérieure à 30000 ans, l'industrie de débitage levallois est un Atérien à indice laminaire important, à pointes pédonculées abondantes et qui possède aussi des pièces foliacées à retouches bifaciales.

Spatule dentée en os (ayant pu servir de peigne de potier) et « brassard d'archer » en schiste de Dar es-Soltane
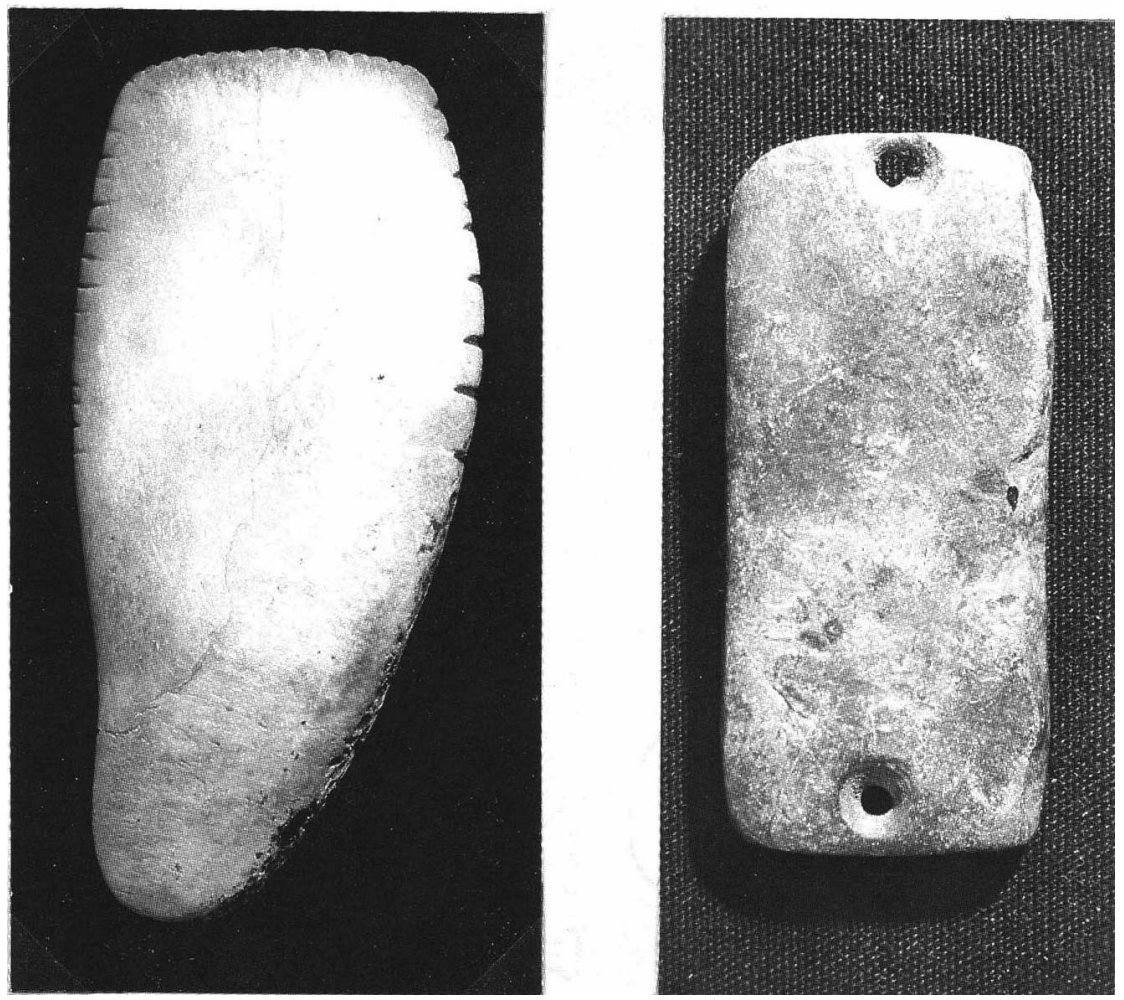

\section{Les hommes de Dar es-Soltane (D. Ferembach)}

6 La grotte I livra des restes humains dans les couches $\mathrm{Cl}$ et $\mathrm{B}$. La couche $\mathrm{Cl}$, du prétendu "Moustérien décadent», livra les restes de deux individus, un enfant d'une dizaine d'années et un adulte âgé de moins de 30 ans, dont le crâne assez bien conservé présente les caractères habituels du type de Mechta el-Arbi*. La couche B 
(Chalcolithique) a livré les restes d'au moins quatre individus plus graciles, appartenant, du moins certains d'entre eux, au type proto-méditerranéen.

7 Plus intéressantes furent les découvertes faites en 1975 par A. Débenath dans le gisement voisin, la Grotte 2, située à $200 \mathrm{~m}$ de la première. Il y releva une stratigraphie comparable à celle de la Grotte 1 et recueillit dans la couche brun-rouge « soltanienne " de nombreux restes humains dont un crâne incomplet (Dar es-Soltane 5) mais à face partiellement conservée et permettant de nombreuses mesures et comparaisons. Cet homme adulte (mort à plus de 50 ans à en juger le degré de synostose des sutures), est incontestablement un Homo sapiens sapiens et tant morphologiquement que métriquement, rien ne s'oppose à voir dans ce fossile un ancêtre possible des Ibéromaurusiens, c'est-à-dire des Hommes de Mechta el-Arbi, dont il ne diffère que par l'accentuation de certains caractères (dimensions transversales, arcades sourcilières) et un aspect plus archaïque, plus robuste. Par sa position stratigraphique dans la couche brun-rouge (soltanienne), l'Homme de Dar es-Soltane 5 est le représentant du type humain de l'Atérien, dans une position intermédiaire entre l'Homme du Djebel Irhoud qui est moustérien et l'Homme de Mechta el-Arbi qui apparaît à l'Ibéromaurusien.

\section{BIBLIOGRAPHIE}

BALOUT L., Préhistoire de l'Afrique du Nord. Essai de chronologie, Paris, A.M.G., 1955.

DEBENATH A., « Le site de Dar es-Soltane II, à Rabat (Maroc). » Bull. et Mém. Soc. d'Anthrop. de Paris, $13^{\text {e }}$ série, t. 3, 1976 p. 181-182.

DEBENATH A., RAYNAL J., TEXIER J.P., « Position stratigraphique des restes humains paléolithiques marocains sur la base des travaux récents ", Comptes rendus de l'Acad. des Sciences, t. 294, série 2, 1982, p. 1247-1250.

FEREMBACH D., « Les restes humains de la grotte Dar es-Soltane 2 (Maroc), Campagne 1975, » Bull et Mém. Soc. d'Anthrop. de Paris, $13^{\mathrm{e}}$ série, t. 3, 1976, p. 183-193.

ROCHE J., « Étude de l'industrie de la grotte de Dar-es-Soltan », Bull. d'Archéol. marocaine, t. 1, 1956, p. 93-118.

RUHLMANN A., La grotte préhistorique de Dar es-Soltan. Coll. Hespéris, Larose, Paris, 1921.

SOUVILLE G. Atlas préhistorique du Maroc atlantique, Paris CNRS, 1973.

INDEX

Mots-clés : Anthropologie, Maroc, Préhistoire 